REVIEW

\title{
Coronary artery stents: identification and evaluation
}

\author{
J Butany, K Carmichael, S W Leong, M J Collins
}

J Clin Pathol 2005;58:795-804. doi: 10.1136/icp.2004.024174

First introduced in the 1980s, the coronary stent has been used to reduce the rate of arterial restenosis. Coronary stent implantation is currently a common procedure performed by interventional cardiologists, and the market for development and design is constantly expanding and evolving. This article was designed to assist pathologists in the accurate identification of coronary stents that are currently available, in addition to some that are no longer being implanted. The stents reviewed here were chosen based on frequency of use and/or occurrence in the literature. Some of the newer models have yet to undergo extensive clinical testing. The summaries accompanying each stent include concise physical descriptions and documented complications, intended to serve as a guide for the investigating pathologist.

See end of article for authors' affiliations

Correspondence to: Dr J Butany, Department of Pathology E4-322, Toronto General Hospital/

University Health Network, Toronto Medical Laboratories, Toronto, ON M5G 2C4, Canada; jagdish.butany@uhn.on.ca

Accepted for publication 14 December 2004
$\mathrm{T}$ he introduction of angioplasty for the treatment of coronary artery disease (CAD) led to the development of a completely new approach to CAD. Until 1994, the use of percutaneous transluminal coronary angioplasty (PTCA) alone as a treatment for coronary artery disease had been increasing steadily. ${ }^{1}$ However, the incidence of restenosis of coronary arteries was an important problem, necessitating repeated interventional procedures in 30\% of patients treated with PTCA alone. ${ }^{1}$

"Percutaneous transluminal coronary angioplasty with stenting has now become the preferred treatment of coronary artery disease for interventional cardiologists"

Restenosis is characterised by neointima formation resulting from the migration of proliferating medial vascular smooth muscle cells to the intima, and the synthesis of matrix components, particularly collagen, with resultant stenosis and constrictive remodelling. ${ }^{2}$ Coronary artery stents were developed to provide a metal scaffolding for the angioplastied vessel, in an attempt to limit negative remodelling. ${ }^{3}$ Sigwart et al first reported the efficacy of stents in reducing restenosis rates in 1987. ${ }^{4}$ By 1994, the Food and Drug Administration (FDA) had approved two stents (Gianturco-Roubin stent and the PalmazSchatz ${ }^{\mathrm{TM}}$ stent), ${ }^{5}$ and additional studies by Serruys et al and Fischman et al confirmed that stenting led to improved clinical outcome over PTCA alone. ${ }^{6}{ }^{7}$ Thus, PTCA with stenting has now become the preferred treatment of CAD for interventional cardiologists. ${ }^{8}$ The FDA has currently approved at least 16 models of stents from nine different manufacturers. ${ }^{5}$

Worldwide, $\$ 2.5$ billion was spent on stents in 2003, and this value is expected to increase to $\$ 4.0$ billion in 2004 . Although a wide array of stent designs and technologies has been introduced into the burgeoning stent market, most coronary stents can still be classified on the basis of: (1) nature of expansion or (2) stent design (table 1).

\section{Characterisation of stents \\ Nature of expansion}

A stent can either be self expanding or balloon expandable. ${ }^{9}$ Multiple studies have shown that these separate modes of expansion differ with respect to late stent expansion and neointima proliferation in stented lesions. ${ }^{10}$ Practising pathologists must consider such differences when deciding on the type of stent being dealt with, before making a diagnosis.

\section{Stent design}

On the basis of design, stents can be divided into three groups: coil, tubular mesh, and slotted tube. ${ }^{9}$ Coil stents are characterised by metallic wires or strips formed into a circular coil shape. In contrast, tubular mesh stents consist of wires wound together in a meshwork, forming a tube. Finally, slotted tube stents are made from tubes of metal from which a stent design is laser cut. Any number of stent designs can be created within a coil, tubular mesh, or slotted tube framework. Furthermore, such designs may have differences in strut pattern and width or overall stent diameter, to name just a few variations. Stent design affects many properties of the stent, such as elastic recoil and rigidity-two undesirable stent characteristics. ${ }^{11}{ }^{12}$ Previous studies have shown that differences in stent design can have a profound influence on late lumen $\operatorname{loss}^{13}$ and neointima proliferation, ${ }^{14}$ thereby affecting restenosis rates and requirements for postprocedural intervention.

Ultimately, stent design should optimise flexibility, trackability, visibility, and biocompatibility (table 2). ${ }^{14}$ Although stent flexibility and trackability are highly dependent on mechanical stent design, radiological visibility and host biocompatibility rely on stent material. Radiopaque gold markers are occasionally added to stents for the sole purpose of improving visualisation, helping to localise the stent during deployment at the target lesion. Although most currently approved stents are made of $316 \mathrm{~L}$

Abbreviations: $C A D$, coronary artery disease; FDA, Food and Drug Administration; MSCTA, multislice computed tomography angiography; PTCA, percutaneous transluminal coronary angioplasty 


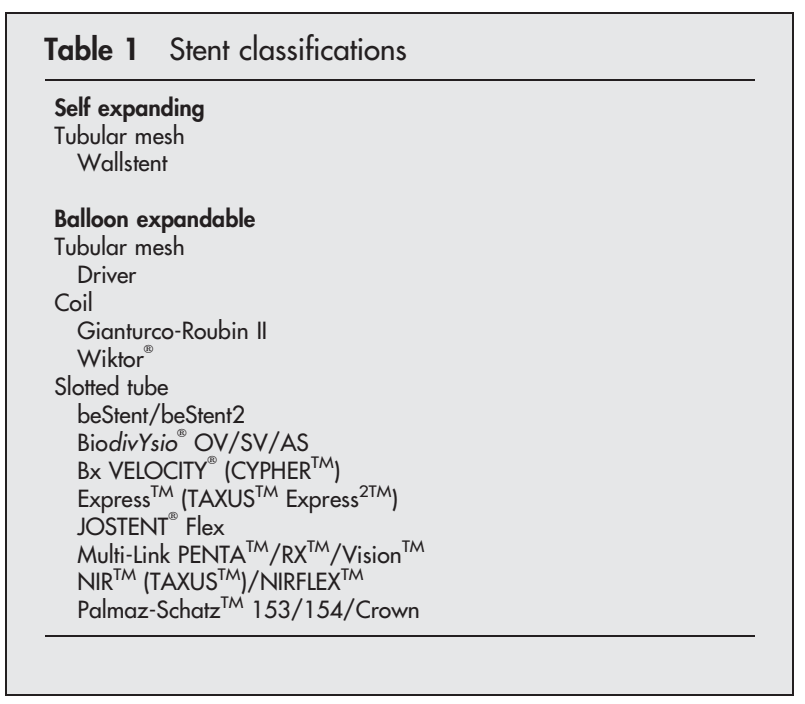

stainless steel, ${ }^{15}$ other materials have been used, such as cobalt chromium in the Multi-Link Vision ${ }^{\mathrm{TM}}$ stent, which is more radiopaque and elicits a less vigorous host response than stainless steel (Guidant pamphlet. Multi-Link VISION Coronary Stent System, 2002).

Although the use of stents reduces restenosis rates when compared with PTCA alone, restenosis still remains a serious problem in patients with CAD. The stenosis of a stented segment can be attributed primarily to the neointima. ${ }^{14}$ Stent design, surface material, and vessel damage related to the procedure have been implicated as predictors of neointima proliferation. ${ }^{14}{ }^{16}$ Because antithrombotic treatment has been shown to have little influence on restenosis rates, the restenosis problem persists in many stented vessels. ${ }^{13}$

In response to this dilemma, manufacturers are now producing drug eluting stents. As of April 2004, at least 35 drug eluting stents were either in use or under investigation worldwide. ${ }^{17}$ Drug eluting stents reduce stent restenosis by delivering drugs directly to the site of vessel injury. The drug, often sirolimus or paclitaxel, acts to inhibit neointimal hyperplasia. Sirolimus (Rapamycin) reduces neointimal hyperplasia by increasing p27 concentrations, inhibiting mitogen stimulated serine/threonine kinase p70S6, and increasing retinoblastoma protein phosphophorylation and cyclin/cyclin dependent kinase complexes. ${ }^{18}$ These changes lead to the reduction of smooth muscle cell proliferation, and reduced inflammatory cell action. ${ }^{19}$ In contrast, paclitaxel is an antiproliferative, microtubule stabilising agent that has also been shown to prevent smooth muscle cell proliferation. ${ }^{20}$ Drugs are released from drug eluting stents by several methods, the most popular involving the use of a polymer matrix. ${ }^{21}$ To illustrate this, many sirolimus eluting stents are made by first coating the stent metal with a primer, followed by coating with a matrix of synthetic polymers mixed with sirolimus. Finally, a layer containing only the polymer is sometimes added, which acts as a diffusion barrier. ${ }^{19}{ }^{21}$ The

\section{Table 2 Desirable stent characteristics}

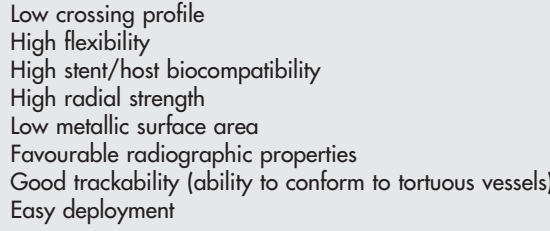

CYPHER $^{\mathrm{TM}}$ sirolimus eluting stent attempts to achieve $1.40 \mu \mathrm{g} / \mathrm{cm}^{2}$ over the stent surface, and the release of sirolimus should last for 30 days. ${ }^{19}$ Clinical studies of drug eluting stents have produced very promising results with regard to the reduction of restenosis, ${ }^{20}$ and their use in clinical practice is becoming common.

\section{"Drug eluting stents reduce stent restenosis by delivering drugs directly to the site of vessel injury"}

Because of the large number of stents implanted each year, the pathologist will probably encounter many stents explanted at autopsy. The purpose of this review is to provide the pathologist with the ability to identify many of the commonly used and older stents in an easy to use guide. We also aim to acquaint the pathologist with the different physical characteristics of these stents, in addition to the major known complications associated with them (table 3). Many such complications of first generation stent models are well known and have been documented in previous studies. For instance, the Wallstent, Palmaz-Schatz stent and Gianturco-Roubin stent each have large bodies of literature describing their clinical complications. Longterm follow up results for many of the more contemporary stents are not yet available, so that pathological investigations of new stent models will help assess the clinical efficacy of these devices.

A multitude of different stents has been available on the market in the short time since stents have gained widespread acceptance. This paper characterises 21 different stent models that are in current use, in addition to some that are no longer being implanted. We have chosen this list of stents based on frequency of occurrence in the literature and hence popularity in clinical trials, but we also include some new and alternative stent models that have yet to undergo extensive testing. They have been divided into non-drug eluting (18) and drug eluting (3) stents, and are listed alphabetically by model name. We have no bias for or against any of the devices listed or a particular stent manufacturer.

\section{beStent}

Model

Available mounted on the beStent Artist balloon platforms. ${ }^{22}$

Type

Balloon expandable, slotted tube.

Technical information

Manufactured and sold by Medtronic (Minneapolis, Minnesota, USA). ${ }^{15}$

\section{Size range}

Length, 8-25 mm; diameter, 2.5-5.5 mm; maximum expansion, $5.8 \mathrm{~mm} .^{15}$

\section{Strut dimensions}

Radial, $0.11 \mathrm{~mm}$ wide $\times 0.07 \mathrm{~mm}$ thick; longitudinal, $0.075 \mathrm{~mm}$ wide $\times 0.07$ mm thick. ${ }^{15}$

\section{Table 3 Common stent complications}

In stent restenosis via neointimal hyperplasia

Side branch occlusion

Poor stent/host biocompatibility

Poor radiographic properties

Post-implantation stent foreshortening

Post-implantation stent expansion

Post-implantation stent migration

Stent related thrombosis 


\section{Physical characteristics}

Serpentine design composed of sinusoidal ring modules linked via sigmoidal link elements. The laser cut stainless steel has two radiopaque gold markers incorporated at the proximal and distal ends. No weld points. ${ }^{15}$

\section{Stent material}

316 L stainless steel. ${ }^{15}$

\section{Radiographical characteristics}

A single gold marker at each end provides the means for easier radiographical localisation.

\section{Additional comments}

First human implant in $1996 .{ }^{15}$ The radial strength of the slotted tube is optimised by an orthogonal locking mechanism and there is virtually no shortening after expansion. ${ }^{15}$ This particular stent was found to display a very low elastic recoil percentage $(2.35 \%$ under 0.2 bar pressure) among 23 tested stents. ${ }^{11}$ In addition, the late minimal lumen diameter of the stent is similar to the initial dilated diameter. ${ }^{11}$ The stent was shown experimentally to collapse at a pressure of $0.70 \mathrm{~atm}^{23}$

\section{beStent2}

\section{Model}

The successor of the beStent is available mounted on Rapid Exchange with or without Perfusion and Over-the-Wire balloon platforms. ${ }^{22}$

Type

Balloon expandable; slotted tube.

Technical information

Manufactured and sold by Medtronic. ${ }^{22}$

\section{Size range}

Length, 9-30 mm; diameter, 2.5-4.0 mm; maximum expansion, $4.5 \mathrm{~mm}^{23}$

\section{Strut dimensions}

Radial, $0.095 \mathrm{~mm}$ wide $\times 0.085 \mathrm{~mm}$ thick; longitudinal, $0.07 \mathrm{~mm}$ wide $\times 0.085 \mathrm{~mm}$ thick. $^{22}$

\section{Physical characteristics}

Flexible radial " $\mathrm{S}$ " crowns and longitudinal " $\mathrm{V}$ " crowns crossing at a junction that rotates during expansion with almost no foreshortening (fig 1). The laser cut stainless steel has two radiopaque gold markers incorporated at the proximal and distal ends. ${ }^{22}$

Stent material

316 L stainless steel. ${ }^{22}$

\section{Radiographical characteristics}

A single gold marker at each end provides means for easier radiographical localisation.

FDA approval

The beStent2 stent was approved in 2000. ${ }^{22}$

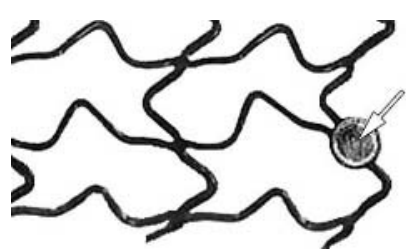

Figure 1 beStent2 by Medtronic The gold radiopaque marker is indicated by a white arrow. Original image taken from website (http://local.teklan.net/ medim/eng/products_details. asp?id $=64$ ).

\section{BiodivYsio}

Model

The models include the Open Cell (BiodivYsio OC), Small Vessel (BiodivYsio SV), and the now unavailable Added Support (BiodivYsio AS) designs.22

Type

Balloon expandable; slotted tube.

\section{Technical information}

Manufactured and sold by Biocompatibles Ltd (an Abbott Laboratories company, Abbott Park, Illinois, USA). ${ }^{22}$

\section{Size range}

- OC: length, 8-28 mm; diameter, 2.75-4.0 mm.

- SV: length, 7-18 mm; diameter, 2.0-2.5 mm.

- AS: length, 8-15 mm; diameter, $2.75-4.0 \mathrm{~mm}^{22}$

\section{Strut dimensions}

- OC: $0.05-0.08 \mathrm{~mm}$ wide $\times 0.09 \mathrm{~mm}$ thick.

- SV: 0.03-0.05 mm wide $\times 0.06 \mathrm{~mm}$ thick.

- AS: $0.05-0.08 \mathrm{~mm}$ wide $\times 0.09 \mathrm{~mm}$ thick. ${ }^{23}$

\section{Physical characteristics}

The BiodivYsio OC and SV stents share an identical strut design of alternating sinusoidal rings consisting of either rectangular or rounded edges. The rings are linked via two turn ( $\mathrm{S}$ shaped) articulations (fig 2). The BiodivYsio AS stent design includes additional articulations in between those present in the OC and SV models. All BiodivYsio stents are coated with phosphorylcholine (PC) Technology ${ }^{\text {TM }}$ to increase stent biocompatibility by mimicking the lipid head group of erythrocyte membranes. ${ }^{24}$

\section{Stent material}

316 L stainless steel coated with polymers containing phosphorylcholine (PC Technology ${ }^{\mathrm{TM}}$ ). ${ }^{22}$

\section{Additional comments}

The phosphorylcholine coating of the BiodivYsio is designed to reduce thrombosis by lowering platelet adhesion and at the same time decreasing the adhesion of proteins. ${ }^{25}$

FDA approval

The BiodivYsio AS stent was approved in September 2000. ${ }^{5}$

\section{Bx Velocity}

\section{Model}

The Bx Velocity is also available in a drug eluting form $\left(\right.$ CYPHER $^{\mathrm{TM}}$ ) or a drug coated form with covalently bound heparin (Hepacoat ${ }^{\mathrm{TM}}$ ). Available mounted on Rapid Exchange or Over-the-Wire balloon platforms. ${ }^{22}$

\section{Type}

Balloon expandable; slotted tube.

\section{Technical information}

Manufactured and sold by Cordis (Miami Lakes, Florida, USA; a Johnson and Johnson Company). ${ }^{22}$

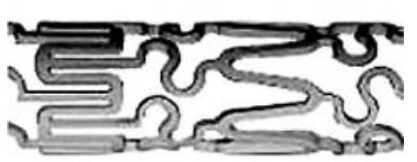

Figure 2 BiodivYsio OV/SV by Biocompatibles Ltd. Original image taken from website (http:// www.user.cityline.ru/ d drgtech/ Biocompatibles. htm). 


\section{Size range}

Length, $8-33 \mathrm{~mm}$; diameter, $2.25-5.0 \mathrm{~mm} .^{22}$

Strut dimensions

Radial, $0.13 \mathrm{~mm}$ wide $\times 0.14 \mathrm{~mm}$ thick. ${ }^{22}$

\section{Physical characteristics}

Sinusoidal ring strut modules linked by flexible "N" shaped flex segments that reduce foreshortening during expansion $(<1.5 \mathrm{~mm})^{22}$ (fig 3).

\section{Stent material}

316 L stainless steel. ${ }^{22}$

\section{Potential complications}

The ISAR-STEREO-2 trial showed that the thick strut $(140 \mu \mathrm{m}) \mathrm{Bx}$ Velocity stent has a high rate of restenosis: $31.4 \%$ of stented vessels had $\geqslant 50 \%$ diameter stenosis at follow up, compared with $17.9 \%$ for the thin strut $(50 \mu \mathrm{m})$ ACS Multi-Link RX ${ }^{\mathrm{TM}}$ stent. $^{26}$

FDA approval

The first human implants were performed in 1999 (France and Italy). In 2000 the drug coated Bx Velocity (Bx Hepacoat) became the first FDA approved drug coated stent. ${ }^{22}$

\section{Driver}

Model

The Driver model includes the Zipper MX. Available mounted on Discrete Technology ${ }^{\mathrm{TM}}$, Rapid Exchange, and Over-theWire balloon platforms. ${ }^{23}$

Type

Balloon expandable; tubular mesh.

Technical information

Manufactured and sold by Medtronic AVE. The Driver is a variation of the previous S7 design. They share an identical sinusoidal strut pattern but the Driver has a smaller strut diameter of $0.09 \mathrm{~mm}$ (Medtronic Vascular Driver website, 2004. Medtronic website).

\section{Size range}

Length, 9-30 mm; diameter, 2.8-4.0 $\mathrm{mm}$; maximum expansion, $4.4 \mathrm{~mm}$.

\section{Strut dimension}

Diameter, $0.091 \mathrm{~mm}$.

\section{Physical characteristics}

The smooth, edgeless, modular design consists of 10 crown sinusoidal rings linked via $1.0 \mathrm{~mm}$ elements (fig 4 ).

\section{Stent material}

Cobalt alloy finished with a chrome rich oxide. The cobalt alloy used in the Driver is more flexible and stronger than 316 L stainless steel, allowing thinner stent struts to be used.

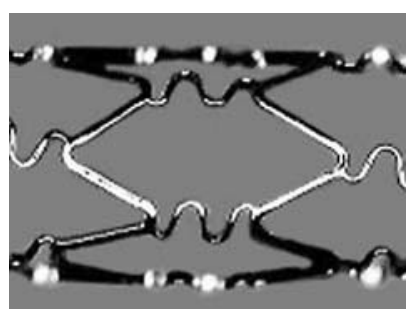

Figure 3 Bx Velocity (CYPHER) by Cordis. Original image taken from website (http:// www.cordis.com)

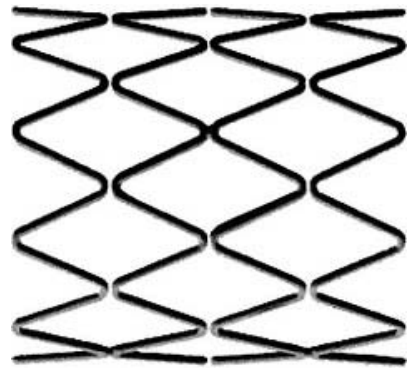

Figure 4 Driver by Medtronic AVE. Original image taken from Driver pamphlet.

Radiographical characteristics

Cobalt alloy provides increased radiographical visualisation compared with stainless steel stents.

\section{FDA approval}

The Driver stent was approved in October 2003 with no reports of implantation outcomes beyond 270 days. ${ }^{5}$

\section{Express $^{\mathrm{TM}}$}

Model

The Express model includes the Express ${ }^{2 \mathrm{TM}}$ and TAXUS Express $^{2 \mathrm{TM}}$ (paclitaxel drug eluting version). Available mounted on Rapid Exchange, Over-the-Wire, and Monorail $^{\mathrm{TM}}$ balloon platforms. ${ }^{22}$

Type

Balloon expandable; slotted tube.

\section{Technical information}

Manufactured and sold by Boston Scientific (Natick, Massachusetts, USA). ${ }^{22}$ All Express stents share an identical strut pattern regardless of delivery system or drug eluting properties.

\section{Size range}

Length, 8-32 mm; diameter, $2.25-5.0 \mathrm{~mm}^{.2}$

\section{Strut dimensions}

Radial, $0.09 \mathrm{~mm}$ wide $\times 0.13 \mathrm{~mm}$ thick; longitudinal, $0.06 \mathrm{~mm}$ wide $\times 0.13 \mathrm{~mm}$ thick. ${ }^{22}$

\section{Physical characteristics}

The modular ring strut pattern consists of two separate module designs: short, narrow sinusoidal Micro ${ }^{\mathrm{TM}}$ elements linked via straight articulations to long, wide sinusoidal Macro $^{\mathrm{TM}}$ elements (Boston Scientific Express website, 2004. Boston Scientific website) (fig 5).

\section{Stent material}

316 L stainless steel. ${ }^{22}$

FDA approval

Approved in September 2002.

\section{Gianturco-Roubin II \\ Type}

Balloon expandable; coil.

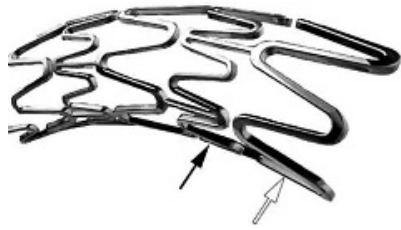

Figure 5 Express (TAXUS Express ${ }^{2}$ ) by Boston Scientific. Micro elements (black arrow) and Macro elements (white arrow) are indicated. Original image taken from TAXUS Express ${ }^{2}$ pamphlet. 
Technical information

Manufactured and sold by Cook Inc (Bloomington, Indiana, USA). ${ }^{15}$

Size range

Length, 12-60 mm; diameter, 2.5-5.0 $\mathrm{mm}^{.15}$

Strut dimensions

$0.172 \mathrm{~mm}$ wide $\times 0.076 \mathrm{~mm}$ thick..$^{1527}$

Physical characteristics

Flat wire coil attached to a single longitudinal strut (fig 6).

Stent material

316 L stainless steel. ${ }^{15}$

\section{Potential complications}

Studies report a restenosis rate of up to $57 \%,{ }^{27}$ and have also shown that the restenosis rate is greater than that of the Palmaz-Schatz stent. ${ }^{28}$ The increased restenosis rate is attributed to greater stent recoil and increased levels of tissue prolapse seen with the Gianturco-Roubin II stent compared with the Palmaz-Schatz stent. Among 22 stents tested in vitro for elastic recoil (under 0.2 bar pressure), the Gianturco-Roubin II had the highest elastic recoil (mean, $18.34 \%$; SD, $2.41 \%$ ), and may need to be overdilated by the interventional cardiologist to compensate for this. ${ }^{11}$

\section{Additional comments}

The Gianturco-Roubin II stent showed a higher procedural success rate than conventional angioplasty with a significantly higher event free survival $(83 \% v 65 \%)$ at one year, and better clinical outcomes in a randomised multicentre study. ${ }^{29}$

\section{FDA approval}

The premier Gianturco-Roubin model was the first coronary stent approved by the FDA in June 1993..$^{30}$ The GianturcoRoubin II stent was approved in June 1996. ${ }^{5}$

\section{JOSTENT ${ }^{\circledR}$ Flex $^{2}$}

Model

The JOSTENT models include the older JOSTENT Plus. In addition, the JOSTENT Coronary Stent Graft model is composed of a layer of PTFE sandwiched between two JOSTENT Flex stents. ${ }^{22}$

Type

Balloon expandable; slotted tube.

\section{Technical information}

Originally manufactured and sold by JOMED (an Abbott Laboratories company) (Abbott Vascular Devices website, 2004).

\section{Size range}

Length, 9-32 $\mathrm{mm}$; diameter, $2.0-5.0 \mathrm{~mm}^{.22}$

Strut dimension

$0.09 \mathrm{~mm}$ wide $\times 0.09 \mathrm{~mm}$ thick. ${ }^{22}$

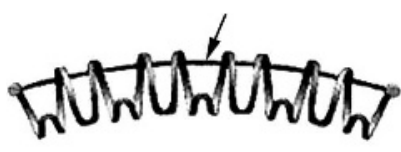

Figure 6 Gianturco-Roubin II by Cook Inc. The longitudinal strut is indicated by a black arrow.

Original image taken from website (http://www.cis.tugraz. at/biomech/Proj1.htm)

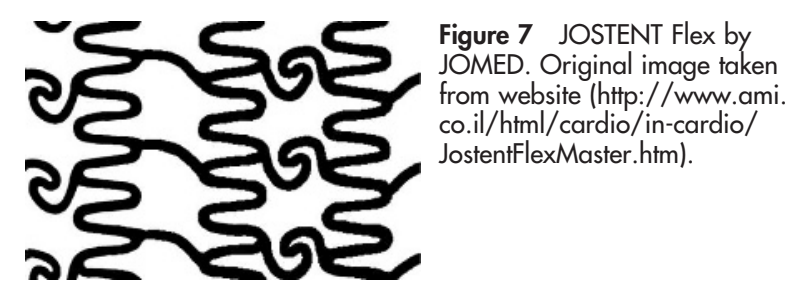

Physical characteristics

The JOSTENT Flex sinusoidal ring modules are linked via alternating flexible spiral and slightly curved link elements (fig 7). The struts are also smooth with rounded edges. ${ }^{22}$

\section{Stent material}

316 L stainless steel. ${ }^{22}$

\section{Potential complications}

The JOSTENT Coronary Stent Graft has been reported to cause a high side branch occlusion rate of up to $18.6 \%$, in some instances resulting in major complications, such as myocardial infarction. ${ }^{31}$ Restenosis at the proximal and distal edges of the JOSTENT Coronary Stent Graft remains a serious limitation of this stent, despite low observed neointimal proliferation at the stent centre. ${ }^{31}$ Studies have shown that the lumen can be completely obscured by artefacts when being visualised by multislice computed tomography angiography (MSCTA). ${ }^{32}$

\section{Additional comments}

Studies have shown that the stent is not superior to conventional angioplasty for small coronary arteries. ${ }^{33}$ Stent graft systems such as the JOSTENT Coronary Stent Grafts may prove to be the preferred treatment for perforations in the coronary arteries, although more studies are needed. ${ }^{31}$

FDA approval

The JOSTENT Coronary Stent Graft was approved in January $2001 .^{522}$

\section{Multi-Link PENTA ${ }^{\text {TM }}$ \\ Type}

Balloon expandable; slotted tube.

Technical information

Manufactured and sold by Guidant (Indianapolis, Indiana, USA)..$^{22}$

\section{Size range}

Length, 8-38 mm; diameter, 2.75-4.0 mm; maximum expansion, $4.5 \mathrm{~mm} .^{22}$

\section{Strut dimensions}

Radial, $0.097 \mathrm{~mm}$ wide $\times 0.124 \mathrm{~mm}$ thick; longitudinal, $0.076 \mathrm{~mm}$ wide $\times 0.091 \mathrm{~mm}$ thick. ${ }^{22}$

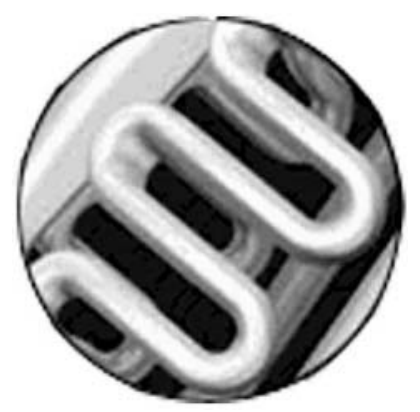

Figure 8 Multi-Link PENTA by Guidant. The five turn ACCESSLINK element is shown. Original image taken from website (http:// www.guidant.jp/products/ penta/reach.shtml). 


\section{Physical characteristics}

Corrugated Multi-Link five crown rounded corner zigzag ring module design linked via five turn ACCESS-LINK ${ }^{\mathrm{TM}}$ elements $^{22}$ (fig 8).

Stent material

316 L stainless steel. ${ }^{22}$

\section{Potential complications}

Side branch occlusion immediately after stenting is not uncommon (up to 25\%) because of the specific slotted tube design. ${ }^{34}$ The Multi-Link stent has a large mounted profile (1.53 mm) compared with many other stents, such as JOSTENT $(1.15 \mathrm{~mm})$, and ranked highest in a study of profile size, among eight other stents. ${ }^{12}$

\section{Additional comments}

In clinical use it was shown to have a higher implantation success rate compared with the Palmaz-Schatz stent, ${ }^{35}$ and also produced lower in stent tissue proliferation as a result of its corrugated ring design. ${ }^{17}$ In a comparison with seven other slotted tube stents, the Multi-Link stent ranked second in a longitudinal flexibility test. ${ }^{12}$ In addition, reopening of stenosed side branches by balloon dilatation is feasible using the Multi-Link, because a $3.5 \mathrm{~mm}$ balloon inflated to $12 \mathrm{~atm}$ through the struts of the Multi-Link can achieve a 94\% balloon expansion, compared with $80 \%$ for the PalmazSchatz and $60 \%$ for the NIR stent. ${ }^{36}$

FDA approval

The Multi-Link PENTA model was approved in 2001. ${ }^{52}$

\section{Multi-Link RX}

Model

The models include the Multi-Link RX PIXEL ${ }^{\mathrm{TM}}$ and ULTRA $^{\mathrm{TM}}$ used in small and large coronary vessels, respectively. $^{22}$

Type

Balloon expandable; slotted tube.

Technical information

Manufactured and sold by Guidant. ${ }^{22}$

\section{Size range}

- PIXEL: length, 8-28 mm; diameter, 2.0-2.5 mm; maximum expansion, $3.0 \mathrm{~mm} .^{22}$

- ULTRA: length, 13-38 mm; diameter, 3.5-5.0 mm; maximum expansion, $5.5 \mathrm{~mm} .{ }^{22}$

\section{Strut dimensions}

- PIXEL: $0.096 \mathrm{~mm}$ wide $\times 0.099 \mathrm{~mm}$ thick

- ULTRA: $0.1 \mathrm{~mm}$ wide $\times 0.13 \mathrm{~mm}$ thick. ${ }^{22}$

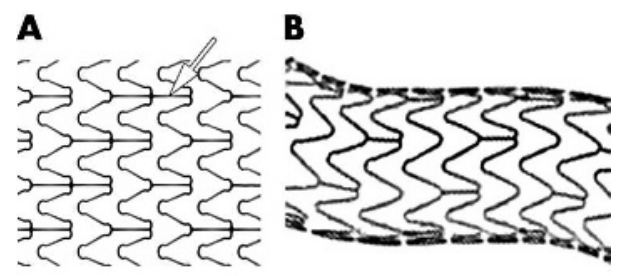

Figure 9 (A) Multi-Link RX PIXEL by Guidant. Additional straight articulation is indicated by a white arrow. Original image taken from website (http://www.guidant.com/products/producttemplates/vi/ us_pixel_intro.shtml). (B) Multi-Link RX ULTRA by Guidant. Original image taken from website (http://www.guidant.com/products) producttemplates/vi/us_ultra.shtml).
Physical characteristics

Corrugated Multi-Link five crown rounded corner zigzag ring module design linked via straight link elements (fig 9A,B). The PIXEL model contains an additional straight link element between modules ${ }^{22}$ (fig 9A).

Stent material

316 L stainless steel.22

\section{Additional comments}

Scaffolding struts are thinner compared with the Bx Velocity $(50 \mu \mathrm{m} v 140 \mu \mathrm{m})$, which is said to account for the lower rate of restenosis $(18 \% \vee 31 \%){ }^{26}$

\section{FDA approval}

The Multi-Link RX ULTRA model was approved in 2000. ${ }^{52}$

\section{Multi-Link Vision \\ Type}

Balloon expandable; slotted tube.

\section{Technical information}

Manufactured and sold by Guidant (Guidant pamphlet. Multi-Link VISION Coronary Stent System, 2002).

\section{Size range}

Length, 8-38 mm; diameter, $2.75-4.0 \mathrm{~mm}$.

\section{Strut dimensions}

$0.081 \mathrm{~mm}$ thick.

\section{Physical characteristics}

Corrugated Multi-Link five crown rounded corner zigzag ring module design linked via single turn link elements (fig 10).

\section{Stent material}

Cobalt chromium alloy.

\section{Radiographical characteristics}

The low nickel super alloy is more radiopaque than stainless steel.

\section{Additional comments}

The cobalt chromium alloy is stronger than stainless steel; therefore, the stent is thinner and made with less material, and occupies less vessel space than the average stainless steel stent. The enhanced biocompatibility of cobalt chromium compared with $316 \mathrm{~L}$ stainless steel was proposed in a study in which vessels stented with the Multi-Link VISION had a low lumen loss, comparable to that of the thinner strut Multi-Link device. ${ }^{37}$

FDA approval

The Multi-Link VISION model was approved in July 2003.

\section{NIR ${ }^{T M}$}

Model

Additional models include the NIROYAL ${ }^{\mathrm{TM}}$ stent, a NIR stent that is plated with gold.

\section{Type}

Balloon expandable; slotted tube.

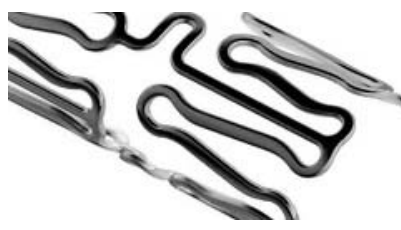

Figure 10 Multi-Link Vision by Guidant. Original image taken from website (http:// www.guidant.com/products/ producttemplates/vi/ US_VISION_Intro.shtml). 
Technical information

Manufactured and sold by Medinol ${ }^{\circledR}$ (Jerusalem, Israel).22

Size range

Length, 9-32 mm; diameter, $2.0-5.0 \mathrm{~mm} .{ }^{22}$

Strut dimension

0.1 mm thick. ${ }^{23}$

Physical characteristics

Sinusoidal ring modules linked via curved link elements (fig 11).

\section{Stent material}

316 L stainless steel. The NIROYAL model has an outer layer of gold..$^{22}$

\section{Potential complications}

The NIR stent has been described as being very stiff compared with other stents. ${ }^{12}$ As with other gold plated stents, the NIROYAL is prone to a higher rate of restenosis by neointimal hyperplasia compared with bare metal stents. ${ }^{38}$ Using MSCTA, the lumen of a vessel treated with the NIROYAL stent was completely obstructed radiographically, ${ }^{32}$ making clinical angiography follow up difficult using MSCTA. Balloon expansion of side branches through the struts of the NIR stent may be difficult, because a $3.5 \mathrm{~mm}$ balloon could only be inflated to $60 \%$ by 12 atm pressure through NIR struts. ${ }^{36}$

\section{Additional comments}

Believed to perform equivalently to the Palmaz-Schatz stent, but also designed to provide increased longitudinal flexibility and trackability during deployment. ${ }^{39}$ The stent was shown experimentally to collapse at a pressure of $1.05 \mathrm{~atm}^{23}$

\section{NIRFLEX ${ }^{\text {TM }}$}

Model

Model premounted on a Rapid Exchange delivery system.

Type

Balloon expandable; slotted tube.

Technical information

Manufactured and sold by Medinol. ${ }^{23}$

Size range

Length, 9-32 mm; diameter, 2.5-4.0 mm; maximum expansion, $5.75 \mathrm{~mm}^{23}$

\section{Strut dimension}

$0.1 \mathrm{~mm}$ thick. ${ }^{23}$

\section{Physical characteristics}

Sinusoidal ring modules consisting of alternating long and short crowns linked via " $Z$ " shaped elements (Medinol NIRFLEX website, 2003. Medinol website) (fig 12).

Stent material

316 L stainless steel. ${ }^{22}$

FDA approval

The NIRFLEX model was approved in October 2003. ${ }^{5}$

Palmaz-Schatz 153

Model

Available mounted on the PAS delivery system. ${ }^{15}$

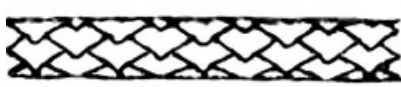

Figure 11 NIR (TAXUS) by Medinol. Original image taken from website (http:// www.hgcardio.com/ptca.htm).

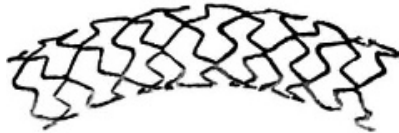

Figure 12 NIRFLEX by Medinol. Original image taken from website (http://www.medinol. com/nirflex.html).

Type

Balloon expandable; slotted tube.

Technical information

Manufactured and sold by Cordis (a Johnson and Johnson Company). ${ }^{15}$

Size range

Length, $15 \mathrm{~mm}$;diameter, $3.0-5.0 \mathrm{~mm}^{.15}$

Strut dimensions

$0.07 \mathrm{~mm}$ thick. ${ }^{22}$

\section{Physical characteristics}

The Palmaz-Schatz 153 model design consists of expandable diamond mesh slotted tubes (fig 13) articulated at specific points by straight link elements.

\section{Stent material}

316 L stainless steel. ${ }^{15}$

\section{Potential complications}

Only one length $(15 \mathrm{~mm})$ was manufactured. More than one stent was needed for the treatment of long lesions. ${ }^{15}$ Delivery of the long stent was hindered (or made impossible) by its rigidity. ${ }^{40}$ The treatment of lesions involving major side branches is not recommended using this particular stent because of its unique tight metal strut design. ${ }^{38}$ The high radiolucency of the Palmaz-Schatz stent makes the accurate assessment of stent diameter by angiography very difficult. ${ }^{41}$ Increased neointimal proliferation and dissection at the proximal and distal ends of the stented segment result from the high pressure required for stent deployment $(20 \mathrm{~atm}) .{ }^{11}$

\section{Additional comments}

Implanted in over 600000 patients, the Palmaz-Schatz stent was found to perform as well as its early successors, ${ }^{27}$ exhibiting a low percentage of subacute thrombosis. ${ }^{42}$ It was first used to introduce the concept of the balloon expandable stent in $1985 .{ }^{43}$ The stent was shown experimentally to collapse at a pressure of $0.65 \mathrm{~atm} .^{23}$

\section{FDA approval}

The first approval of the Palmaz-Schatz stent was in August 1994, further approval was granted to the medium and long models in June 1997.

\section{Palmaz-Schatz 154 \\ Model}

The models include the Spiral Coronary Palmaz-Schatz stent and its successor the Improved Spiral Coronary PalmazSchatz stent. Available mounted on the PowerGrip ${ }^{\mathrm{TM}}$ Rapid Exchange delivery system. ${ }^{15}$

Type

Balloon expandable; slotted tube.

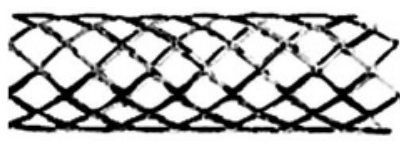

Figure 13 Palmaz-Schatz 153/ 154 by Cordis. Original image taken from website (http:// hippo.med.hirosaki-u.ac.jp/ $\sim$ radio/IVR/palmazstent.html). 
Technical information

Manufactured and sold by Cordis (a Johnson and Johnson Company)..$^{15}$

Size range

- Spiral: length, 8-18 mm; diameter, 3.0-5.0 mm. ${ }^{15}$

- Improved Spiral: length, $15 \mathrm{~mm}$; diameter, $3.0-5.0 \mathrm{~mm} .^{15}$

Strut dimensions

$0.09 \mathrm{~mm}$ thick. ${ }^{22}$

\section{Physical characteristics}

Expandable diamond mesh identical to the 153 model (fig 13), articulated at specific points via spiral link elements. The initial Spiral model was modified to create the Improved Spiral by cutting the stent with 10 rows and five articulations rather than 12 rows and six articulations. ${ }^{15}$

\section{Stent material}

316 L stainless steel. ${ }^{15}$

\section{Additional comments}

Found to possess twice the mechanical strength of the PS153 precursor and was shown experimentally to collapse at a pressure of $1.26 \mathrm{~atm}^{23}$

\section{Palmaz-Schatz Crown \\ Model}

Available mounted on the PowerGrip Rapid Exchange delivery system. ${ }^{15}$

Type

Balloon expandable; slotted tube.

Technical information

Manufactured and sold by Cordis (a Johnson and Johnson Company). ${ }^{15}$

Size range

Length, $15-30 \mathrm{~mm}$; diameter, $3.0-4.0 \mathrm{~mm} .^{15}$

Strut dimensions

$0.07 \mathrm{~mm}$ thick. ${ }^{22}$

Physical characteristics

The slotted tube is designed with a continuous sinusoidal pattern showing no articulation sites.

\section{Stent material}

316 L stainless steel. ${ }^{15}$

\section{Potential complications}

The Palmaz-Schatz Crown ranked highest in a stiffness test among 13 other stents tested. ${ }^{44}$

\section{Additional comments}

The stent was shown experimentally to collapse at a pressure of $0.71 \mathrm{~atm}^{24}$

\section{Wallstent \\ Type}

Self expanding; tubular mesh.

\section{Technical information}

Initially manufactured and sold by Schneider (Europe), ${ }^{15}$ currently distributed by Boston Scientific (Boston Scientific Wallstent website, 2004. Boston Scientific website).

\section{Size range}

Length, $15-50 \mathrm{~mm}$; diameter, $4.0-6.0 \mathrm{~mm} .^{15}$

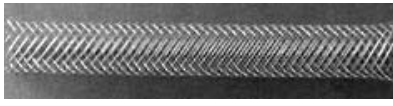

Figure 14 Wallstent by Boston Scientific. Original image taken from website (http:// www.geocities.co.jp/HeartLandSumire/6231/gfx.htmS)

Strut dimension

Diameter, $0.1 \mathrm{~mm} .{ }^{22}$

Physical characteristics

Cylindrical braided mesh design consisting of 24 wires (fig 14). There are also two available mesh angles $\left(>140^{\circ}\right.$ and $<120^{\circ}$ ) that affect radial force strength and the extent of foreshortening. ${ }^{43}$

\section{Stent material}

Platinum inner core covered with a cobalt based alloy layer. ${ }^{15}$

\section{Potential complications}

Difficulties in precise positioning as a result of foreshortening of up to $20 \%$ on expansion. ${ }^{27}$ In addition, the mesh design is known to cause side branch entrapment. ${ }^{15}$ Because of the self expanding design, there is a chronic radial pressure exerted on the vessel walls that can exacerbate neointima proliferation. It has been stated that this proliferation is balanced by post-procedural stent expansion. ${ }^{10}$

\section{Additional comments}

First patented in $1982,{ }^{43}$ the Wallstent was the first clinically tested stent (1986). ${ }^{27}$ It was found to maintain the same radiographical characteristics over a 10 year period of implantation, with no calcification or lesion progression in those who were restenosis free after the first six months. ${ }^{45}$ In addition, a study showed an $18 \%$ loss in diameter of the stented segment over a five year period followed by virtually no loss $(0.3 \%)$ in diameter over the subsequent five years. ${ }^{45}$

FDA approval

The first human implant was performed in 1986 ${ }^{15}$; FDA approval was given for the Boston Scientific Magic Wallstent in September $1998 .^{5}$

\section{Wiktor $^{\oplus}$}

Model

The Wiktor stent is also available with Hepamed ${ }^{\mathrm{TM}}$ coating. ${ }^{15}$

Type

Balloon expandable; coil.

\section{Technical information}

Manufactured and sold by Medtronic Interventional Vascular. ${ }^{15}$

Size range

Length, $16 \mathrm{~mm}$; diameter, $3.0-4.5 \mathrm{~mm} .^{15}$

\section{Strut dimensions}

Diameter, $0.127 \mathrm{~mm}^{15}$

\section{Physical characteristics}

Single wire helical sinusoidal coil.

\section{Stent material}

Tantalum. ${ }^{15}$

\section{Potential complications}

Using MSCTA, the Wiktor stent showed strong artefacts and the lumen of the stent was totally obstructed-this was attributed to the tantalum material from which the stent is made. ${ }^{32}$ Only negligible artefacts are expected when using magnetic resonance imaging. ${ }^{32}$ Protrusion of the intima into the stented lumen may be more common in the Wiktor stent 
than in slotted tube stents because of its open wire design. ${ }^{46}$ Insertion of an intravascular ultrasound catheter into the Wiktor stent must be performed with extreme care, because the increased radiopacity of the tantalum material can lead to stent damage during intravascular ultrasound. Among 22 stents tested in vitro for elastic recoil (under 0.2 bar pressure), the Wiktor had the third highest elastic recoil percentage. ${ }^{11}$

\section{Additional comments}

The open design of the Wiktor may allow more access to side branches and provide the stent with additional flexibility and conformity. ${ }^{46}$ In a three point bend test, the unexpanded Wiktor had a mean (SD) measured stiffness of $0.5(0.2) \mathrm{g}$ force $/ \mathrm{mm}$, the lowest among 13 stents tested, conferring high flexibility to this stent. ${ }^{12}$

\section{FDA approval}

The Wiktor stent was approved in June 1997. ${ }^{15}$

\section{DRUG ELUTING STENTS \\ CYPHER}

Model

The CYPHER drug eluting stent is available mounted on Over-the-Wire or Rapid Exchange balloon platforms (CYPHER website, 2004. Cordis (J\&J) website).

Type

Balloon expandable; slotted tube.

\section{Technical information}

Manufactured and sold by Cordis (a Johnson and Johnson Company).

Size range

Length, $18-33 \mathrm{~mm}$; diameter, $2.50-3.50 \mathrm{~mm}$.

\section{Strut dimensions}

Radial, $0.13 \mathrm{~mm}$ wide $\times 0.14 \mathrm{~mm}$ thick. ${ }^{22}$

\section{Physical characteristics}

Maintains all the characteristics of the Bx Velocity, sinusoidal ring strut modules linked by flexible N shaped Flex Segments (fig 3).

\section{Eluted drug}

Sirolimus. Initial drug concentration of $1.4 \mu \mathrm{g} / \mathrm{mm}^{2}$ of stent, eluted over 30 days.

Stent material

316 L stainless steel.

\section{Potential complications}

Reports of post-implantation thrombosis (including up to $20 \%$ resulting in death) to the FDA within 10 months after its approval led to the release of an official FDA statement (February 2004). ${ }^{47}$ Professionals are asked to adhere to the manufacturer's recommendations when intending to use this stent, including matching stent and vessel diameters, implanting only within previously untreated vessels, and maintaining an adequate antiplatelet regimen. ${ }^{19} 47$

\section{FDA approval}

The CYPHER stent became the first drug eluting stent approved by the FDA in April 2003. ${ }^{5}$

\section{TAXUS $^{\text {TM }}$ \\ Type \\ Balloon expandable; slotted tube.}

Technical information

Manufactured and sold by Medinol. ${ }^{22}$

\section{Size range}

Length, $15 \mathrm{~mm}$; diameter, 3.0 and $3.5 \mathrm{~mm} .{ }^{22}$

\section{Strut dimension}

0.1 mm thick. ${ }^{22}$

\section{Eluted drug}

Paclitaxel. The initial paclitaxel concentrations are $1.02 \mu \mathrm{g} /$ $\mathrm{mm}^{2}$ ( $85 \mu \mathrm{g}$ total) and $2.04 \mu \mathrm{g} / \mathrm{mm}^{2}$ (171 $\mu \mathrm{g}$ total) for the slow and fast release formulations, respectively. ${ }^{22}$

\section{Physical characteristics}

Maintains all the characteristics of the NIR stent, sinusoidal ring modules linked via curved link elements (fig 11).

\section{Stent material}

316 L stainless steel. ${ }^{22}$

\section{Additional comments}

Studies showed a reduced occurrence of myocardial infarction nine to 12 months after implantation when using the TAXUS model compared with the bare metal stent. In addition, 70\% lower angiographic restenosis was seen, together with decreased target lesion revascularisation, nine and 12 months after implantation, respectively. ${ }^{48}$

\section{TAXUS Express ${ }^{2}$}

Type

Balloon expandable; slotted tube.

\section{Technical information}

Manufactured and sold by Boston Scientific (Boston Scientific pamphlet. TAXUS Express ${ }^{2}$ Paclitaxel-Eluting Coronary Stent System, 2003).

\section{Size range \\ Length, 8-32 mm; diameter, 2.25-5.00 $\mathrm{mm}$.}

\section{Strut dimensions}

Radial, $0.091 \mathrm{~mm}$ wide $\times 0.13 \mathrm{~mm}$ thick; longitudinal, $0.06 \mathrm{~mm}$ wide $\times 0.13 \mathrm{~mm}$ thick. ${ }^{22}$

\section{Eluted drug}

Paclitaxel. The slow release formulation has an initial drug concentration of $1.0 \mu \mathrm{g} / \mathrm{mm}^{2}$ of stent.

\section{Physical characteristics}

Maintains the characteristics of the Express models. The modular ring strut pattern consists of two separate module designs: short, narrow sinusoidal Micro elements linked via straight articulations to long, wide sinusoidal Macro elements (Boston Scientific Express website, 2004. Boston Scientific website) (fig 5).

Stent material

316 L stainless steel. ${ }^{22}$

FDA approval

The TAXUS Express ${ }^{2}$ drug eluting stent was approved in March 2004. ${ }^{5}$

\section{Authors' affiliations \\ J Butany, K Carmichael, S W Leong, M J Collins, Department of Pathology, Toronto General Hospital/University Health Network, Toronto Medical Laboratories, Toronto, ON M5G 2C4, Canada}




\section{REFERENCES}

1 Bittl JA. Advances in coronary angioplasty. N Engl J Med 1996;335: 1290-302

2 Franco CD, Hou G, Bendeck MP. Collagens, integrins, and the discoidin domain receptors in arterial occlusive disease. Trends Cardiovasc Med 2002; 12:143-8.

3 Wentzel JJ, Krams R, Schuurbiers JC, et al. Relationship between neointima thickness and shear stress after Wallstent implantation in human coronary arteries. Circulation 2001;103:1740-5.

4 Sigwart U, Puel J, Mirkovitch V, et al. Intravascular stents to prevent occlusion and restenosis after transluminal angioplasty. N Engl J Med 1987:316:701-6.

5 Devices at the US Food and Drug Administration website, 2004. FDA website (http://www.fda-gov)

6 Serruys PW, de Jaegere P, Kiemeneij F, et al. A comparison of balloonexpandable-stent implantation with balloon angioplasty in patients with coronary artery disease. Benestent study group. N Engl J Med 1994:331:489-95.

7 Fischman DL, Leon MB, Baim DS, et al. A randomized comparison of coronary-stent placement and balloon angioplasty in the treatment of coronary artery disease. Stent restenosis study investigators. N Engl J Med 1994:331:496-501

8 Rotter M, Pfiffner D, Maier W, et al. Interventional cardiology in Europe 1999. Eur Heart J 2003;24:1164-70.

9 Balcon R, Beyar R, Chierchia S, et al. Recommendations on stent manufacture, implantation and utilization. Study group of the working group on coronary circulation. Eur Heart J 1997; 18:1536-47.

10 Konig A, Schiele TM, Rieber J, et al. Stent design-related coronary artery remodeling and patterns of neointima formation following self-expanding and balloon-expandable stent implantation. Catheter Cardiovasc Interv 2002:56:478-86.

11 Barragan P, Rieu R, Garitey V, et al. Elastic recoil of coronary stents: a comparative analysis. Catheter Cardiovasc Interv 2000;50:112-19.

12 Ormiston JA, Dixon SR, Webster MW, et al. Stent longitudinal flexibility: a comparison of 13 stent designs before and after balloon expansion. Catheter Cardiovasc Interv 2000;50:120-4.

13 Kastrati A, Dirschinger J, Boekstegers P, et al. Influence of stent design on 1 year outcome after coronary stent placement: a randomized comparison of five stent types in 1,147 unselected patients. Catheter Cardiovasc Interv 2000:50:290-7.

14 Hoffmann R, Jansen C, Konig A, et al. Stent design related neointimal tissue proliferation in human coronary arteries; an intravascular ultrasound study. Eur Heart J 2001;22:2007-14.

15 Serruys PW, Rensing B. Handbook of coronary stents. London: Dunitz; Distributed in the USA by Fulfilment Center Taylor and Francis (Kentucky, USA), 1998.

16 Hoffmann R, Mintz GS, Haager PK, et al. Relation of stent design and sten surface material to subsequent in-stent intimal hyperplasia in coronary arterie determined by intravascular ultrasound. Am J Cardiol 2002;89:1360-4.

17 Shah PK. Inflammation, neointimal hyperplasia, and restenosis: as the leukocytes roll, the arteries thicken. Circulation 2003;107:2175-7.

18 Decker T, Hipp S, Ringshausen I, et al. Rapamycin-induced G1 arrest in cycling B-CLL cells is associated with reduced expression of cyclin D3, cyclin E, cyclin A, and survivin. Blood 2003;101:278-85.

19 Cheng-Lai A, Frishman WH. Sirolimus-eluting coronary stents: novel devices for the management of coronary artery disease. Am J Ther 2004; 1 1:218-28.

20 Chieffo A, Colombo A. Polymer-based paclitaxel-eluting coronary stents. Clinical results in de novo lesions. Herz 2004;29:147-51.

21 al-Lamee K, Cook D. Polymer coating techniques for drug-eluting stents. Med Device Technol 2003;14:12-4

22 Serruys PW, Rensing B. Handbook of coronary stents. London: Dunitz; Distributed in the USA by Fulfilment Center Taylor and Francis (Kentucky, USA), 2002, xiii, 366.

23 Schrader SC, Beyar R. Evaluation of the compressive mechanical properties of endoluminal metal stents. Cathet Cardiovasc Diagn 1998;44:179-87.

24 Malik N, Gunn J, Shepherd L, et al. Phosphorylcholine-coated stents in porcine coronary arteries: in vivo assessment of biocompatibility. J Invasive Cardiol 2001;13:193-201.

25 Grenadier E, Roguin A, Hertz I, et al. Stenting very small coronary narrowing $(<2 \mathrm{~mm})$ using the biocompatible phosphorylcholine-coated coronary stent. Catheter Cardiovasc Interv 2002;55:303-8.
26 Pache J, Kastrati A Mehilli J, et al. Intracoronary stenting and angiographic results: strut thickness effect on restenosis outcome (ISAR-STEREO-2) trial. J Am Coll Cardiol 2003;41:1283-8.

27 Colombo A, Tobis J. Techniques in coronary artery stenting. London: Martin Dunitz; Distributed in the United States by Blackwell Science (Malden, Massachusetts, USA), 2000.

28 Lansky AJ, Roubin GS, O'Shaughnessy CD, et al. Randomized comparison of GR-II stent and Palmaz-Schatz stent for elective treatment of coronary stenoses. Circulation 2000;102:1364-8.

29 Rodriguez A, Bernardi V, Fernandez $M$, et al. In-hospital and late results of coronary stents versus conventional balloon angioplasty in acute myocardial infarction (GRAMI trial). Gianturco-Roubin in acute myocardial infarction. Am J Cardiol 1998;81:1286-91.

30 Hermiller JB, Fry ET, Peters TF, et al. Late coronary artery stenosis regression within the Gianturco-Roubin intracoronary stent. Am J Cardiol 1996;77:247-51

31 Gercken U, Lansky AJ, Buellesfeld L, et al. Results of the Jostent coronary stent graft implantation in various clinical settings: procedural and follow-up results. Catheter Cardiovasc Interv 2002;56:353-60

32 Maintz D, Juergens KU, Wichter T, et al. Imaging of coronary artery stents using multislice computed tomography: in vitro evaluation. Eur Radiol 2003:13:830-5.

33 Mehilli J, Kastrati A, Dirschinger J, et al. A randomized trial comparing the hand-mounted JoStent with the premounted Multi-Link Duet stent in patients with coronary artery disease. Catheter Cardiovasc Interv 2001;54:414-19.

34 Ehara S, Shimada K, Kobayashi Y, et al. Short- and long-term outcomes of compromised side branches after Multi-Link stent implantation. Heart Vessels 2002:16:86-90.

35 Fujiwara T, Sasao H, Endo A, et al. Clinical and angiographic results after MULTI-LINK stent implantation and their relation to aggregation of risk factors: two-year follow-up. Circ J 2002;66:949-53.

36 Kuroda N, Kobayashi Y, Yamamoto Y, et al. Limited balloon expansion through the struts of the Palmaz-Schatz and NIR stents compared with the Multi-Link stent. Jpn Circ J 2000;64:883-5.

37 Kereiakes DJ, Cox DA, Hermiller JB, et al. Usefulness of a cobalt chromium coronary stent alloy. Am J Cardiol 2003;92:463-6.

38 Kastrati A, Schomig A, Dirschinger J, et al. Increased risk of restenosis after placement of gold-coated stents: results of a randomized trial comparing goldcoated with uncoated steel stents in patients with coronary artery disease. Circulation 2000; 101:2478-83.

39 Rutsch W, Kiemeneij F, Colombo A, et al. Clinical and angiographic results with the NIR stent: first international NIR endovascular stent study (FINESS-II). Int J Cardiovasc Intervent 2000;3:143-51

40 Sayin T, Berkalp B, Akyurek O, et al. Angiographic and clinical follow-up after coronary implantation of the ACS Multilink Duet stent: a single center experience. Jpn Heart J 2001;42:409-16.

41 Kimura T, Yokoi H, Nakagawa Y, et al. Three-year follow-up afte implantation of metallic coronary-artery stents. N Engl J Med 1996:334:561-6.

42 Keighley CS, Urban P, Killer II, et al. Palmaz-Schatz coronary stent implantation without intravascular ultrasound and without subsequen anticoagulation: clinical outcome. J Invasive Cardiol 1996;8:185-90

43 Adam A, Daly S, Mueller R. Textbook of metallic stents. Oxford: Isis Medical Media, 1997

44 Ormiston JA, Webster MW, Ruygrok PN, et al. Six-month angiographic and 12-month clinical follow-up of Multilink long $(25$ to $35 \mathrm{~mm}$ ) stents for long coronary narrowings in patients with angina pectoris. Am J Cardiol 2002;90:222-6.

45 Carrie D, Elbaz M, Andrieu $M$, et al. Ten-year clinical and angiographic follow-up of coronary wallstent. Am J Cardiol 2000;85:95-8, A8.

46 Fluck DS, Chenu $P$, Mills $P$, et al. Is provisional stenting the effective option? The WIDEST study (Wiktor stent in de novo stenosis). Widest trial investigators' group. Heart 2000;84:522-8.

47 Choi SB. CYPHER coronary stents and risk of thrombosis. Can Med Assoc 2003; 169:218.

48 Stone GW, Ellis SG, Cox DA, et al. One-year clinical results with the slowrelease, polymer-based, paclitaxel-eluting TAXUS stent: the TAXUS-IV trial. Circulation 2004; 109:1942-7. 